\title{
Vegetation cover predicts temperature in nests of the hawksbill sea turtle: implications for beach management and offspring sex ratios
}

\author{
Stephanie Jill Kamel ${ }^{*}$ \\ Center for Population Biology, Department of Evolution and Ecology, College of Biological Sciences, \\ University of California, 1 Shields Ave, Davis, California 95616, USA
}

\begin{abstract}
Whether a sea turtle embryo develops into a male or a female depends, as with many other reptiles, on the temperature during incubation of the eggs. With sea turtles, warm temperatures produce $100 \%$ females and, thus, increasing global temperatures have the potential to significantly alter offspring sex ratios. Nest-site selection provides a potential mechanism by which females might adjust the sex of their offspring, but necessitates a reliable cue which provides information about the thermal properties of a nest. Overstory vegetation cover was found to significantly predict temperatures in nests of the hawksbill sea turtle Eretmochelys imbricata. Nests placed under high vegetation cover are significantly cooler and remain within the male-producing range of temperatures throughout incubation. Interestingly, metabolic heating of the developing clutch is less pronounced under vegetation, further reinforcing the importance of this nesting habitat with respect to the production of males. This underscores the importance of preserving natural vegetation cover at hawksbill nesting beaches in order to maintain the thermal diversity of nesting sites and, potentially, mitigate the impacts of increasing global temperatures.
\end{abstract}

KEY WORDS: Hawksbill $\cdot$ Sex ratio $\cdot$ Vegetation cover $\cdot$ Metabolic heating $\cdot$ Nest-site choice Climate change

\section{INTRODUCTION}

In egg-laying species, the nest environment influences a wide range of offspring traits, such as size (Brown \& Shine 2004), performance (Shine \& Harlow 1996, Shine et al. 1997, Gillespie \& Wratten 2011), and, in species with temperature-dependent sex determination, gender (Mrosovsky \& Provancha 1992, Roosenburg 1996). For sea turtles, phenotypic sex is determined by the temperature during the middle third of incubation, with warmer temperatures leading to the development of female offspring within a thermal tolerance range of 25 to $35^{\circ} \mathrm{C}$ (Yntema \& Mrosovsky 1982, Ackerman 1997). Average global surface temperatures are predicted to increase by at least $0.1^{\circ} \mathrm{C}$ per decade: within the Caribbean basin, temperatures are expected to increase by between 1 and $6^{\circ} \mathrm{C}$, depending upon specific emissions scenarios (IPCC 2001, Brohan et al. 2006). Increasing temperatures present a challenge for these species, and a primary conservation issue is to understand whether, in response to higher ambient temperatures, individuals will be able to adjust the sex ratio of their offspring (Hawkes et al. 2007).

The potential for females to adjust offspring sex ratios becomes all the more critical in species threatened with extinction. Hawksbill sea turtles Eretmochelys imbricata are listed as Critically Endangered by the IUCN and, globally, populations have 
declined by $>80 \%$ from historical levels (Meylan \& Donnelly 1999, Mortimer \& Donnelly 2008). Over the past decades, hawksbills have been the focus of conservation efforts, most of which have been aimed at reducing the take of turtles and their eggs. However, the alteration of primary sex ratios as a result of climate change could also have serious consequences for population stability. The data on sex ratios appear to bear this out: in both Antigua and Brazil, hawksbill hatchling sex ratios are highly female biased (Godfrey et al. 1999, Glen \& Mrosovsky 2004). In fact, Glen \& Mrosovsky (2004) show that fewer males were produced in Pasture Bay, Antigua in 2003 as compared to 1989, possibly in response to increasing ambient temperatures.

Hawksbills are unique among sea turtles as they tend to nest in or near vegetation (Diamond 1976, Horrocks \& Scott 1991, Kamel \& Mrosovsky 2005, Ditmer \& Stapleton 2012). In fact, many hawksbill populations tend to nest in heterogeneous environments, with nesting beaches comprised of a combination of open, sandy areas and more heavily vegetated patches (Kamel \& Mrosovsky 2005). These beach microhabitats vary widely in their thermal profiles (Kamel \& Mrosovsky 2006a) and provide ample opportunity for females to select among different nest temperatures. Previous research has identified individual variation in female nesting preferences, with some females preferring forested areas, while others show a preference for open sand (Kamel \& Mrosovsky 2005, 2006b). Substantial variability has also been found in sand temperatures across beach microhabitats, with sand temperatures in the forest being significantly cooler than in less shaded areas (Kamel \& Mrosovsky 2006a). These sand temperature data provide suggestive evidence that vegetation cover can reliably predict sex ratios, since sand temperatures in the forest are frequently in the male-producing range (i.e. below the pivotal temperature, the temperature producing equal sex ratios when eggs are incubated under constant conditions; Mrosovsky \& Pieau 1991). However, it is unknown how tightly vegetation cover is linked to individual nest temperatures and thus how consistently it can be used by females as a predictive cue.

Quantifying the relationship between vegetation cover and nest temperature is particularly important since sea turtles lay large clutches of 100 to 200 eggs, and the subsequent warming of nests during development (so-called metabolic heating; Broderick et al. 2001, Zbinden et al. 2006) might eliminate any correlation between sand and nest temperatures. In fact, some studies have shown metabolic heating during the thermosensitive period of sexual differentiation (TSP) to be about $1^{\circ} \mathrm{C}$ (Zbinden et al. 2006). Therefore, if sand temperatures are below or near pivotal, metabolic heating may cause feminization of clutches thought to be laid in 'male-producing areas' and thus invalidate vegetation cover as a useful cue.

This paper investigates whether individual nests vary significantly in their thermal properties and documents the link between overstory vegetation cover and temperature to assess its utility as a potential cue for females and as a means of predicting nest sex ratios. Metabolic heating during incubation was also measured to determine if it obscures any relationship between vegetation cover and temperature. Finally, the effect of metabolic heating and vegetation cover on nest hatching success was examined.

\section{MATERIALS AND METHODS}

\section{Study site}

Guadeloupe, French West Indies, hosts one of the largest hawksbill nesting populations in the Caribbean (Kamel \& Delcroix 2009). Trois Ilets beach is located on the western coast of Marie-Galante, a small island $40 \mathrm{~km}$ southeast of the main island of Guadeloupe. The beach runs in a north-south direction and comprises $2.0 \mathrm{~km}$ of usable nesting habitat. Beach width varies between 1 and $9 \mathrm{~m}$ and is backed by a coastal littoral forest. The beach can thus be divided into 4 different zones: forest (completely surrounded by trees), forest border (near the forest but not completely surrounded), low-lying vegetation (presence of grass or beach creepers) and open sand (largely free of overstory vegetation, save the occasional overhanging branch). Each beach zone also corresponds to a particular amount of overstory vegetation cover: open sand ( 0 to $10 \%$ ), low-lying vegetation (11 to $40 \%$ ), forest border (41 to $70 \%$ ) and forest ( 71 to $100 \%)$. Tidal variations along the beach are negligible $(<0.3 \mathrm{~m})$, except during storms, which typically occur between August and October. The main nesting season occurs between May and October, with a peak in July.

\section{Nest measurements}

Hobo Water Temp Pro data loggers (Onset Computer) were placed in a total of 24 nests and 24 control sites. Twelve pairs of data loggers were placed between 9 and 30 June during the 2002 nesting sea- 
son, and 12 more, between 7 and 27 June during the 2004 nesting season. To do so, nests were excavated no later than $8 \mathrm{~h}$ after egg deposition, with the eggs' original orientations maintained to minimize potential disturbance of the developing embryos. The number of eggs in a clutch was counted, and then half the eggs were returned to the nest, a data logger was placed in the centre of the clutch, its depth in relation to the sand surface was measured and the remaining eggs were returned. A second data logger was placed at the same depth at a control site $1 \mathrm{~m}$ away and under the same amount of vegetation cover. The amount of vegetation cover directly above the nest was measured with a densiometer, which is commonly used to assess canopy density (see Kamel \& Mrosovsky 2005).

Nests were monitored nightly, and, once hatchlings had emerged, the number of hatched eggs (only eggshell remained) and the number of unhatched eggs were recorded. Data loggers were removed from both the nest and the control site to download the temperature data. Hourly temperature readings were averaged to give mean daily temperature readings for each data logger. The data loggers had a resolution of $0.01^{\circ} \mathrm{C}$ and were guaranteed to fall within an accuracy range of $\pm 0.18^{\circ} \mathrm{C}$, but were calibrated prior to use.

\section{Data analyses}

Incubation duration was calculated as the number of days between the night a nest was laid and the night the hatchlings emerged. From this, the TSP, which occurs during the middle third of development, was estimated (Yntema \& Mrosovsky 1982). Given that there is a time lag between hatching and emergence, the TSP was also calculated assuming a development time $4 \mathrm{~d}$ shorter than the incubation duration (see Godfrey \& Mrosovsky 1997 for details on determining this interval). Given that the 2 estimates did not differ significantly, results using the middle third of incubation are given. Metabolic heating was calculated as the difference between nest temperature and sand temperature at the control site. As the effect of metabolic heating on sexual differentiation was a main issue under study, comparisons of metabolic heating were restricted to the TSP. Regression analyses were conducted to assess the influence of temperature and vegetation cover on hatching success. Day of the year of oviposition and year were included as variables in the analyses. Given that a pivotal temperature has not been estimated for hawksbills in Guadeloupe, a pivotal temperature of $29.2^{\circ} \mathrm{C}$ was assumed, calculated from hawksbill clutches collected in Antigua (Mrosovsky et al. 1992). All analyses were run in JMP (Version 9.0.0, SAS Institute), and results are presented as means $( \pm \mathrm{SD})$.

\section{RESULTS}

Data loggers were recovered from a total of 21 hawksbill nests and their associated control sites (Table 1). Nest temperatures varied throughout embryonic development, with nests placed in the forest showing less temperature fluctuation than nests laid in the open sand (Fig. 1). There was no significant effect of oviposition date or year on nest temperatures $\left(\mathrm{r}^{2}=0.02, \mathrm{p}=0.53\right)$; thus, these parameters were not included in subsequent analyses. Overall, mean temperatures during incubation for nests in the forest were significantly cooler than temperatures for both nests in the low-lying vegetation and the open

Table 1. Eretmochelys imbricata. Mean (SD in parentheses) of thermal characteristics and hatching success of 21 hawksbill nests and associated control sites across 4 beach zones at Trois Ilets beach, Guadeloupe. TSP: thermosensitive period of sexual differentiation

\begin{tabular}{|lcccccccc|}
\hline Zone & $\begin{array}{c}\text { Vegetation } \\
\text { cover } \\
(\%)\end{array}$ & $\begin{array}{c}\text { Incubation } \\
\text { duration } \\
(\mathrm{d})\end{array}$ & $\begin{array}{c}\text { Temperature } \\
\text { during the TSP }\left({ }^{\circ} \mathrm{C}\right) \\
\text { Nest }\end{array}$ & $\begin{array}{c}\text { Metabolic } \\
\text { Control }\end{array}$ & $\begin{array}{c}\text { Temperature during during } \\
\text { the TSP }\left({ }^{\circ} \mathrm{C}\right)\end{array}$ & $\begin{array}{c}\text { Hatching } \\
\text { Nest }\end{array}$ & $\begin{array}{c}\text { Hation }\left({ }^{\circ} \mathrm{C}\right) \\
\text { Control }\end{array}$ \\
$\begin{array}{l}\text { Opuccess } \\
(\mathrm{n}=5)\end{array}$ \\
$\begin{array}{c}\text { Low-lying vege- } \\
\text { tation (n=6) }\end{array}$ & $20.1(6.3)$ & $59.8(1.1)$ & $29.98(0.72)$ & $28.39(0.25)$ & $1.01(0.2)$ & $30.62(0.91)$ & $28.77(0.43)$ & $85.4(10.8)$ \\
$\begin{array}{l}\text { Forest border } \\
(\mathrm{n}=4)\end{array}$ & $53.8(11.1)$ & $60.9(1.8)$ & $28.47(0.42)$ & $28.05(0.47)$ & $1.03(0.11)$ & $29.76(0.34)$ & $28.36(0.55)$ & $91.3(5.6)$ \\
$\begin{array}{c}\text { Forest } \\
(\mathrm{n}=6)\end{array}$ & $89.2(4.9)$ & $64.6(1.5)$ & $27.77(0.53)$ & $27.13(0.18)$ & $0.72(0.14)$ & $28.90(0.45)$ & $27.50(0.41)$ & $91.7(4.5)$ \\
\hline
\end{tabular}




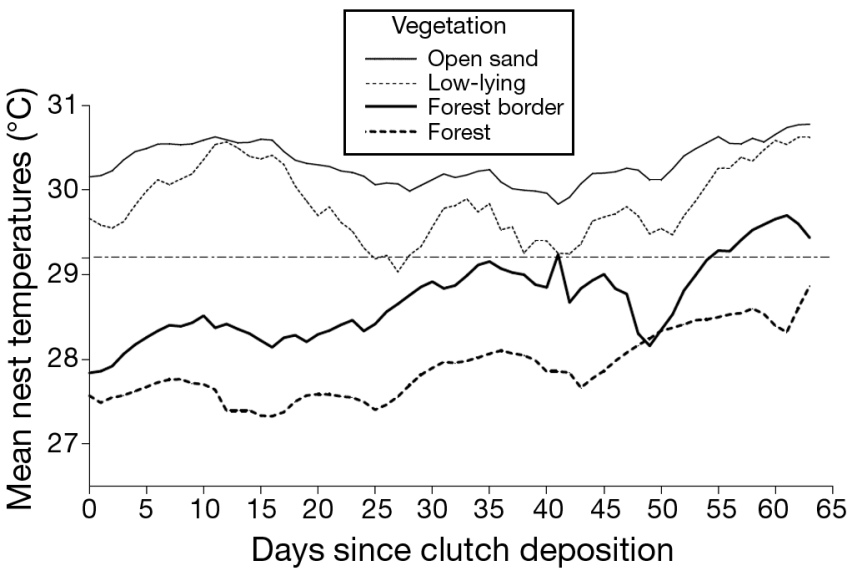

Fig. 1. Eretmochelys imbricata. Mean daily nest temperatures $\left({ }^{\circ} \mathrm{C}\right)$ throughout incubation of nests from each of the 4 beach zones (open sand, low-lying vegetation, forest border, forest). Pivotal temperature of $29.2^{\circ} \mathrm{C}$ estimated by Mrosovsky et al. (1992) for hawksbill clutches from Jumby Bay, Antigua, is indicated by the horizontal dashed line

sand (ANOVA: $F_{3,16}=5.93, \mathrm{p}=0.006$; Tukey post hoc tests: open vs. forest, $\mathrm{p}<0.01$; low-lying vegetation vs. forest, $\mathrm{p}<0.05$ ). Vegetation cover above a nest was significantly negatively correlated with both sand temperatures $\left(\mathrm{r}^{2}=0.63, \mathrm{p}<0.001\right)$ and nest temperatures $\left(r^{2}=0.42, p=0.002\right)$ throughout incubation. Vegetation cover was also correlated with incubation duration: eggs in heavily shaded nests took longer to hatch than those in warmer, more unshaded nests $\left(\mathrm{r}^{2}=0.59, \mathrm{p}=0.01\right)$.

All 21 nests displayed a similar pattern of metabolic heating, with relatively low levels in the first half of incubation followed by a steady increase from the end of the middle third, and peaking during the final third of incubation (Fig. 2). The amount of metabolic heating during the TSP varied greatly among nests $\left(\bar{x}=0.98 \pm 0.24^{\circ} \mathrm{C}\right.$, range: 0.54 to $\left.1.45^{\circ} \mathrm{C}\right)$. In fact, metabolic heating was significantly negatively correlated with vegetation cover $\left(\mathrm{r}^{2}=0.52, \mathrm{p}<0.0001\right)$, with nests in the forest exhibiting less metabolic heating than more open nests (Fig. 3). Metabolic heating was not significantly correlated with clutch size $(\bar{x}=166 \pm 43)$, suggesting that larger clutches do not get warmer, even after controlling for vegetation cover $\left(\mathrm{r}^{2}=0.002, \mathrm{p}=0.87\right)$.

The relationship between vegetation cover and nest temperature remained significant during the TSP $\left(r^{2}=0.57, p=0.0002\right.$; Fig. 4$)$, which suggests that nests under vegetation remained cooler than open nests and that metabolic heating within nests was not enough to overwhelm this cooling effect of the vegetation. When restricting analyses to nests with $>40 \%$

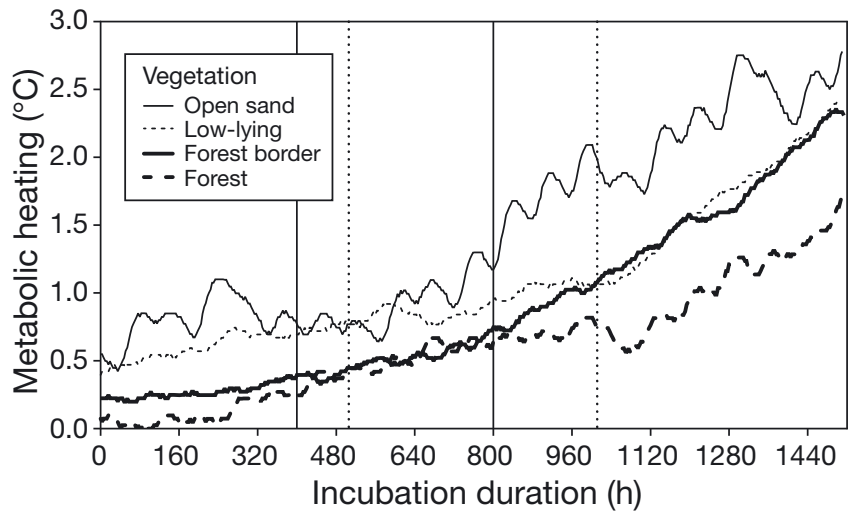

Fig. 2. Eretmochelys imbricata. Metabolic heating of nests from each of the 4 beach zones (open sand, low-lying vegetation, forest border, forest). Solid vertical lines indicate the middle third of incubation for the open nests; dotted vertical lines indicate the middle third of incubation for the shaded nests

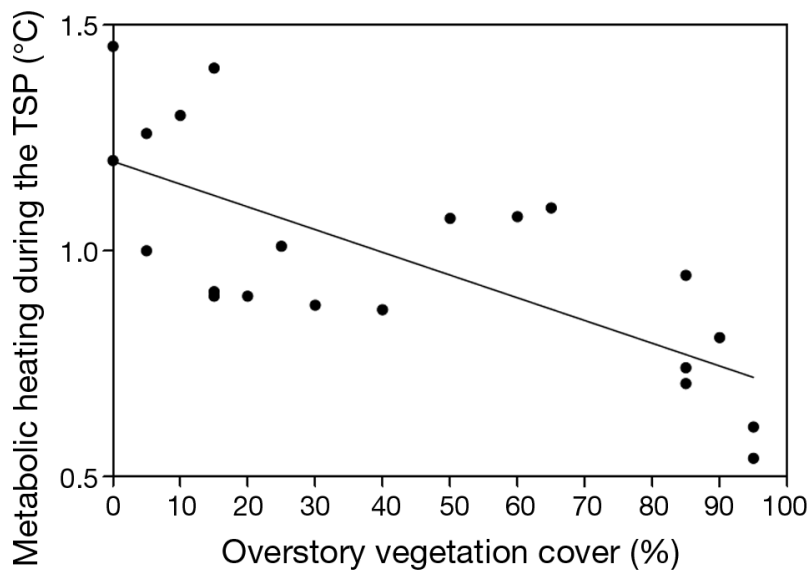

Fig. 3. Eretmochelys imbricata. Relationship between the amount of metabolic heating $\left({ }^{\circ} \mathrm{C}\right)$ during the thermosensitive period of sexual differentiation (TSP) and percent vegetation cover above a nest $(\mathrm{n}=21)$

vegetation cover (i.e. nests on the forest border and in the forest), the correlation between nest temperatures and vegetation cover remained significant $\left(\mathrm{r}^{2}=\right.$ $0.38, p=0.05)$, suggesting that even among vegetation sites, more cover implies a greater cooling effect. However, 10 of 21 nests (48\%) had both the mean and standard deviation of temperatures below the estimated pivotal temperature of $29.2^{\circ} \mathrm{C}$ (Mrosovsky et al. 1992) during the TSP, and all of them had $>40 \%$ vegetation cover (Fig. 4).

Hatching success of the 21 nests was uniformly high $(\bar{x}=90.96 \pm 6.03 \%)$, and was not significantly correlated with vegetation cover, clutch size, metabolic heating, or temperature either during the TSP or throughout incubation. 


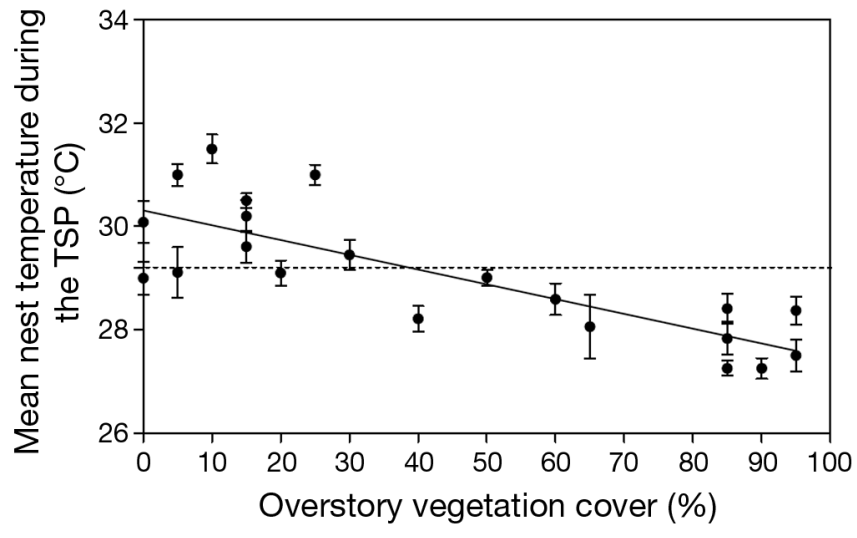

Fig. 4. Eretmochelys imbricata. Relationship between mean $( \pm \mathrm{SD})$ nest temperature $\left({ }^{\circ} \mathrm{C}\right)$ during the thermosensitive period of sexual differentiation (TSP) and percent vegetation cover above a nest $(\mathrm{n}=21)$. Pivotal temperature of $29.2^{\circ} \mathrm{C}$ estimated by Mrosovsky et al. (1992) for hawksbill clutches from Jumby Bay, Antigua, is indicated by the horizontal dashed line

\section{DISCUSSION}

The temperature of a sea turtle nest during incubation is important for the successful development of hatchlings and the determination of their sex. Unlike most other sea turtle species, many hawksbill females prefer to nest near or under dense vegetation cover (Kamel \& Mrosovsky 2005, Ficetola 2007). The beach at Trois Ilets is relatively pristine, with littoral forest remaining intact for much of its length, and presents females with many habitat options (i.e. open sand, low-lying vegetation, or forest) during nest placement. Vegetation cover above the nest is a strong and significant predictor of sand temperature, both at control sites and within nests. The significant relationship between vegetation cover and nest temperature indicates that warming of the clutch during development is not sufficient to decouple this correlation. In fact, metabolic heating during the TSP is significantly negatively correlated with vegetation cover, such that nests in the forest experience less warming, despite a similar clutch size to eggs laid in more open areas.

The differences in sand temperatures across beach habitats are consistent with previous work documenting broad-scale thermal patterns on this beach (Kamel \& Mrosovsky 2006a), whereby temperatures in the forest are often within the male-producing range. In theory, if sand temperatures are close to pivotal then metabolic heating could push nest temperatures over this threshold and feminize potentially male-producing nests. While metabolic heating during the middle third of incubation averages about $1^{\circ} \mathrm{C}$, similar to that found in clutches of other sea turtle species (Broderick et al. 2001, Glen \& Mrosovsky 2004, Zbinden et al. 2006, Patino-Martinez et al. 2012), large deviations are seen at the extremes: in nests laid in the open sand and nests laid in the forest. On the one hand, this suggests a positive feedback between warmer sand temperatures and increased heating of the egg mass. On the other, vegetation cover appears to provide a strong buffer against increased warming, which actually results in lower than average amounts of metabolic heat. In fact, sand temperatures in the forested areas are low enough such that, even with metabolic heating, none of the nests located in those areas experiences temperature excursions over the estimated pivotal temperature of $29.2^{\circ} \mathrm{C}$ (Mrosovsky et al. 1992). This corresponds to $48 \%$ of all nests and, if a higher pivotal temperature estimate of $29.6^{\circ} \mathrm{C}$ (Mrosovsky et al. 2009 ) is used, then this proportion increases to $67 \%$ rendering this habitat essential for ensuring production of male hatchlings. Overall, the bulk of metabolic heating in all nests occurs during the late stages of development, well after sexual differentiation is thought to occur.

Direct assessments of sex ratio in other turtle species have found that, under certain conditions, vegetation cover can be a significant predictor of hatchling sex (Vogt \& Bull 1984, Janzen 1994, Kolbe \& Janzen 2002). Due in large part to the endangered status of sea turtles, direct assessment of clutch sex ratios through histological examination of the gonads is not often possible, and sand temperatures are commonly used as indirect estimators of sex ratio (e.g. Oz et al. 2004, Booth \& Freeman 2006, Patino-Martinez et al. 2012). Recent work on hawksbills has demonstrated that nest temperatures are a highly significant predictor of sex ratio in natural nests (Mrosovsky et al. 2009). Furthermore, this finding is robust to $10 \mathrm{~d}$ deviations in the TSP, suggesting that nest temperatures are an accurate proxy for estimating clutch sex ratios.

The fact that offspring sex is environmentally determined allows nesting females to potentially manipulate this critical aspect of population demography (Morjan 2003). Nevertheless, nest-site selection and the proximate (and particularly thermal) cues used by female sea turtles are still poorly understood (Wood \& Bjorndal 2000). Previous studies have largely focused on ambient or nest temperatures during egg deposition as mechanisms of nest-site selection, although these measures are highly variable throughout incubation. Overstory vegetation cover should function as a more reliable sex-determining 
cue, because it remains stable during incubation and has been shown to correlate well with the thermal environment of nests in other turtle species (Vogt \& Bull 1984, Janzen 1994, Weisrock \& Janzen 1999, Morjan \& Janzen 2003). In the case of hawksbills the significant correlation between vegetation cover and nest temperature during the TSP suggests a biologically relevant cue for females to utilize. Previous work on this population has demonstrated that females do in fact have very specific microhabitat preferences, with some females consistently preferring open sand and others preferring forested areas, both within and between nesting seasons. Indeed, this preference is robust to changes in both environmental and reproductive variables, with estimates of consistency (i.e. repeatability $=0.7$ ) in nest-site preference among the highest reported for behavioral traits (Kamel \& Mrosovsky 2005, 2006b). Different females are thus consistently producing different offspring sex ratios, and this behaviour seems to be relatively inflexible. However, longer term monitoring of behavioural preferences is required for a greater understanding of the degree to which individual females can alter their nesting locations with respect to climatic changes or whether modifications will be constrained to occur over evolutionary time scales.

These results have important implications for hawksbill conservation practices and highlight the importance of maintaining natural vegetation cover at nesting beaches. Historically, beaches used by Caribbean hawksbills were abutted by thick maritime forest and coastal shrubs which have now been removed for development, a situation commonly seen in Antigua, Barbados, Guadeloupe and other Caribbean islands (Watts 1987, McIntosh et al. 2003, Kamel \& Mrosovsky 2006a, Harewood 2007). Previous studies have demonstrated that non-native cover, largely in the form of coconut palms Cocos nucifera, does not provide the same cooling effect as the more dense maritime forest (Glen \& Mrosovsky 2004, Kamel \& Mrosovsky 2006a). For example, in Guadeloupe, sand temperatures under coconut palms are similar to sand temperatures in open areas on the natural beach and significantly warmer than areas covered by coastal forest, despite having equivalent amounts of shade. Given that different vegetation types provide very different shade qualities, the loss of native vegetation cover on many hawksbill nesting beaches is a substantial concern. Interestingly, even nests under intermediate amounts of cover experienced temperatures well below pivotal, suggesting that mitigation efforts potentially need not include complete reforestation of hawksbill beaches. The use of vegetation 'islands' composed solely of native vegetation rather than a mixture of native and non-native types (e.g. beach-creepers Ipomoea pes-caprae and coconut palms which have been shown to minimally influence sand temperatures) might provide a comprise between the needs of developers and the thermal requirements of hawksbills.

Another point to note is that native vegetation cover did not negatively influence hatching success in this study. This result differs from recent work on hawksbills in Antigua, which showed that clutches laid in vegetated areas have lower hatching success than nests laid in open areas (Ditmer \& Stapleton 2012). However, the authors note that they did not assess how differing vegetation types may influence hatch success and point out that further research is needed to determine how individual plant species and vegetation structure might influence hatch success. Furthermore, vegetation is known to play an important role in mitigating the negative effects of erosion due to increasing sea levels, as well the increased frequency and intensity of storm events (Fish et al. 2005).

Given that levels of climate warming are predicted to increase between 0.3 and $7.5^{\circ} \mathrm{C}$ over the next century in North America (IPCC 2001, Zwiers 2002), conservation strategies must take into account how habitat changes might influence sea turtle demography on both local and regional scales. For example, genetic analyses, as well as tagging and satellite tracking, have demonstrated that a high level of mixing occurs in the Caribbean basin (Diaz-Fernandez et al. 1999, Blumenthal et al. 2009), particularly among males (Velez-Zuazo et al. 2008), supporting the idea that male dispersal is important for maintaining genetic exchange among rookeries (Karl et al. 1992). Guadeloupe might be an important regional source of male turtles, and more work elucidating their reproductive contributions to the wider Caribbean population is required. More generally, explaining the existence of highly female-biased sex ratios in sea turtles remains a challenge, both theoretically and for the conservation of species in an increasingly warmer world.

Acknowledgements. I thank A. Quinn, E. Delcroix and J. Chevalier for assistance in the field, the Direction Régionale de l'Environnement (DIREN) Guadeloupe and the Office National de la Forêt (ONF) Guadeloupe for permission to conduct work at Trois Ilets. Funding was provided by the Natural Sciences and Engineering Research Council of Canada and the National Science Foundation. 


\section{LITERATURE CITED}

Ackerman RA (1997) The nest environment and the embryonic development of sea turtles. In: Lutz PL, Musick JA (eds) The biology of sea turtles. CRC Press, Boca Raton, FL, p 83-106

Blumenthal JM, Abreu-Grobois FA, Austin TJ, Broderick AC and others (2009) Turtle groups or turtle soup: dispersal patterns of hawksbill turtles in the Caribbean. Mol Ecol 18:4841-4853

Booth DT, Freeman C (2006) Sand and nest temperatures and an estimate of hatchling sex ratio from the Heron Island green turtle (Chelonia mydas) rookery: southern Great Barrier Reef. Coral Reefs 25:629-633

> Broderick AC, Godley BJ, Hays GC (2001) Metabolic heating and the prediction of sex ratios for green turtles (Chelonia mydas). Physiol Biochem Zool 74:161-170

- Brohan P, Kennedy JJ, Harris I, Tett SFB, Jones PD (2006) Uncertainty estimates in regional and global observed temperature changes: a new data set from 1850. J Geophys Res 111:D12106, doi: 10.1029/2005JD006548

> Brown GP, Shine R (2004) Maternal nest-site choice and offspring fitness in a tropical snake (Tropidonophis mairii, Colubridae). Ecology 85:1627-1634

$>$ Diamond AW (1976) Breeding biology and conservation of hawksbill turtles Eretmochelys imbricata, on Cousin Island, Seychelles. Biol Conserv 9:199-215

Diaz-Fernandez R, Okayama T, Uchiyama T, Carrillo E and others (1999) Genetic sourcing for the hawksbill turtle, Eretmochelys imbricata, in the northern Caribbean region. Chelonian Conserv Biol 3:296-300

> Ditmer MA, Stapleton SP (2012) Factors affecting hatch success of hawksbill sea turtles on Long Island, Antigua, West Indies. PLoS ONE 7:e38472

Ficetola GF (2007) The influence of beach features on nesting of the hawksbill turtle Eretmochelys imbricata in the Arabian Gulf. Oryx 41:402-405

> Fish MR, Cote IM, Gill JA, Jones AP, Renshoff S (2005) Predicting the impact of sea-level rise on Caribbean sea turtle nesting habitat. Biol Conserv 19:482-491

> Gillespie M, Wratten SD (2011) Oviposition preference of Lycaena salustius for, and larval performance on, a novel host plant: an example of ecological fitting. Ecol Entomol 36:616-624

> Glen F, Mrosovsky N (2004) Antigua revisited: the impact of climate change on sand and nest temperatures at a hawksbill turtle (Eretmochelys imbricata) nesting beach. Glob Change Biol 10:2036-2045

Godfrey MH, Mrosovsky N (1997) Estimating the time between hatching of sea turtles and their emergence from the nest. Chelonian Conserv Biol 2:581-585

Godfrey MH, D'Amato AF, Marcovaldi MA, Mrosovsky N (1999) Pivotal temperature and predicted sex ratios for hatchling hawksbill turtles from Brazil. Can J Zool 77: 1465-1473

Harewood A (2007) Impacts of coastal development on the nesting behaviour, nest success and hatchling viability of hawksbill turtles (Eretmochelys imbricata) in Barbados, West Indies. PhD dissertation, University of the West Indies, St. Michael, Barbados

> Hawkes LA, Broderick AC, Godfrey MH, Godley BJ (2007) Investigating the potential impacts of climate change on a marine turtle population. Glob Change Biol 13:923-932

- Horrocks JA, Scott McA (1991) Nest site location and nest success in the hawksbill turtle, Eretmochelys imbricata, in Barbados, West Indies. Mar Ecol Prog Ser 69:1-8

IPCC (Intergovernmental Panel on Climate Change) (2001) Climate change 2001: the scientific basis. Contribution of Working Group I to the third assessment report of the IPCC. Cambridge University Press, Cambridge

Janzen FJ (1994) Vegetational cover predicts the sex ratio of hatchling turtles in natural nests. Ecology 75:1593-1599

> Kamel SJ, Delcroix E (2009) Nesting ecology of the hawksbill turtle, Eretmochelys imbricata, in Guadeloupe, French West Indies from 2000-07. J Herpetol 43: 367-376

Kamel SJ, Mrosovsky N (2005) Repeatability of nesting preferences in the hawksbill sea turtle, Eretmochelys imbricata, and their fitness consequences. Anim Behav 70: 819-828

- Kamel SJ, Mrosovsky N (2006a) Deforestation: risk of sex ratio distortion in hawksbill sea turtles. Ecol Appl 16: 923-931

Kamel SJ, Mrosovsky N (2006b) Inter-seasonal maintenance of individual nest site preferences in hawksbill sea turtles. Ecology 87:2947-2952

> Karl SA, Bowen BW, Avise JC (1992) Global population genetic structure and male-mediated gene flow in the green turtle (Chelonia mydas)—RFLP analyses of anonymous nuclear loci. Genetics 131:163-173

> Kolbe JJ, Janzen FJ (2002) Impact of nest-site selection on nest success and nest temperature in natural and disturbed habitats. Ecology 83:269-281

McIntosh I, Goodman K, Parrish-Ballantine A (2003) Tagging and nesting research on hawksbill turtles (Eretmochelys imbricata) at Jumby Bay, Long Island, Antigua, West Indies. University of Georgia, Athens, GA

Meylan AB, Donnelly M (1999) Status justification for listing the hawksbill turtle (Eretmochelys imbricata) as Critically Endangered on the 1996 IUCN Red List of Threatened Animals. Chelonian Conserv Biol 3: 200-224

> Morjan CL (2003) How rapidly can maternal behavior affecting primary sex ratio evolve in a reptile with environmental sex determination. Am Nat 162:205-219

Morjan CL, Janzen FJ (2003) Nest temperature is not related to egg size in a turtle with temperature-dependent sex determination. Copeia 366-372

Mortimer JA, Donnelly M (2008) Eretmochelys imbricata. IUCN Red List of Threatened Species, Version 2010.4. IUCN, Gland

Mrosovsky N, Pieau C (1991) Transitional range of temperature, pivotal temperatures and thermosensitive stages for sex determination in reptiles. Amphib-Reptilia 12: 169-179

> Mrosovsky N, Provancha J (1992) Sex ratio of hatchling loggerhead sea turtles: data and estimates from a 5-year study. Can J Zool 70:530-538

Mrosovsky N, Bass A, Corliss LA, Richardson JI, Richardson TH (1992) Pivotal and beach temperatures for hawksbill turtles nesting in Antigua. Can J Zool 70:1920-1925

Mrosovsky N, Kamel SJ, Diez CE, van Dam RP (2009) Methods of estimating natural sex ratios of sea turtles from incubation temperatures and laboratory data. Endang Species Res 8:147-155

> Oz M, Erdogan A, Kaska Y, Dusen S and others (2004) Nest temperatures and sex-ratio estimates of loggerhead turtles at Patara beach on the southwestern coast of Turkey. Can J Zool 82:94-101

Patino-Martinez J, Marco A, Quinones L, Hawkes L (2012) A 
potential tool to mitigate the impacts of climate change to the Caribbean leatherback sea turtle. Glob Change Biol 18:401-411

Roosenburg WM (1996) Maternal condition and nest site choice: an alternative for the maintenance of environmental sex determination? Am Zool 36:157-168

Shine RT, Harlow PS (1996) Maternal manipulation of offspring phenotypes via nest-site selection in an oviparous lizard. Ecology 77:1808-1817

Shine R, Madsen TRL, Elphick MJ, Harlow PS (1997) The influence of nest temperatures and maternal brooding on hatchling phenotypes in water pythons. Ecology 78: $1713-1721$

Velez-Zuazo X, Ramos WD, van Dam RP, Diez CE, AbreuGrobois A, McMillan WO (2008) Dispersal, recruitment and migratory behaviour in a hawksbill sea turtle aggregation. Mol Ecol 17:839-853

Vogt RC, Bull JJ (1984) Ecology of hatchling sex ratio in map

Editorial responsibility: Matthew Godfrey,

Beaufort, North Carolina, USA turtles. Ecology 65:582-587

Watts D (1987) The West Indies: patterns of development, culture, and environmental change since 1492. Cambridge University Press, Cambridge

Weisrock DW, Janzen FJ (1999) Thermal and fitness-related consequences of nest location in painted turtles (Chrysemys picta). Funct Ecol 13:94-101

Wood DW, Bjorndal KA (2000) Relation of temperature, moisture, salinity and slope to nest site selection in loggerhead sea turtles. Copeia 2000:119-128

Yntema CL, Mrosovsky N (1982) Critical periods and pivotal temperatures for sexual differentiation in loggerhead sea turtles. Can J Zool 60:1012-1016

Zbinden JA, Margaritoulis D, Arlettaz R (2006) Metabolic heating in Mediterranean loggerhead sea turtle clutches. J Exp Mar Biol Ecol 334:151-157

> Zwiers FW (2002) Climate change: the 20 year forecast. Nature 416:690-691

Submitted: October 10, 2012; Accepted: December 11, 2012

Proofs received from author(s): February 8, 2013 